Special Issue of the 8th International Advances in Applied Physics and Materials Science Congress (APMAS 2018)

\title{
Radiation Vulcanization of EPDM Rubber with Polyfunctional Monomers
}

\author{
E. Manaila ${ }^{a}$, G. Craciun ${ }^{a, *}$, M.D. Stelescu ${ }^{b}$ And D. Ighigeanu ${ }^{a}$ \\ ${ }^{a}$ National Institute for Laser, Plasma and Radiation Physics, Electron Accelerators Laboratory, \\ 409 Atomistilor St., Magurele, Romania \\ ${ }^{b}$ National R\&D Institute for Textile and Leather - Leather and Footwear Research Institute, \\ 93 Ion Minulescu St, Bucharest, Romania
}

\begin{abstract}
The most important stage in ethylene-propylene-terpolymer rubber processing technology is vulcanization/cross-linking. The effect of polyfunctional monomers as triallylcyanurate, triallylisocyanurate, trimethylopropane trimethacrylate, and zinc diacrylate on the crosslink density of ethylene-propylene-terpolymer rubber processed by electron beam irradiation using a $5.5 \mathrm{MeV}$ electron accelerator was presented. The dependence of cross-link density on the irradiation dose was also determined in the dose range of 50 to $500 \mathrm{kGy}$. The results have showed that the crosslink density is very sensitive to the polyfunctional monomers use.
\end{abstract}

DOI: 10.12693/APhysPolA.135.1061

PACS/topics: rubber, polyfunctional monomers, irradiation, dose, properties

\section{Introduction}

Most rubbers, excepting thermoplastic elastomers, require curing. The process is normally done by sulphur, accelerators or peroxides. An alternative to these curing systems is the processing by means of ionizing radiations which is very clean, requires less energy and permits greater processing speed. Also, ionizing radiations can induce chemical reactions at any temperature in the solid, liquid and gas phase even without using catalysts $[1,2]$. The goal of the paper is to present the effect of some polyfunctional monomers (PFMs) as triallylcyanurate (TAC), triallylisocyanurate (TAIC), trimethylopropane trimethacrylate (TMPT) and zinc diacrylate (ZDA) and irradiation dose on ethylene-propylene-terpolymer rubber (EPDM) cross-linked by electron beam irradiation.

\section{Materials and equipments}

The following raw materials were used: EPDM rubber Nordel 4760, polyethylene glycol PEG 4000, antioxidant Irganox 1010 and polyfunctional monomers (TAC, TAIC, TMPT and ZDA). For the preparation of EPDM/PFMs blends 100 phr EPDM, 1 phr Irganox 1010 and 3 phr PFMs were added. The process variables were: temperature $60-80^{\circ} \mathrm{C} \pm 5^{\circ} \mathrm{C}$, friction ratio $1: 1.1$ and total blending time $7 \mathrm{~min}$. The obtained samples are referred below as fallowing: EPDM, EPDM/TAC, EPDM/TAIC, EPDM/TMPT and EPDM/ZDA [2]. The samples irradiation was performed in atmospheric conditions and at room temperature of $25^{\circ} \mathrm{C}$, using the linear electron accelerator of $5.5 \mathrm{MeV}$, ALID 7 . The electron beam

*corresponding author; e-mail: gabriela.craciun@inflpr.ro dose rate was fixed at $5 \mathrm{kGy} / \mathrm{min}$ in order to accumulate doses between 50 and $500 \mathrm{kGy}$. The sol-gel analysis and crosslink density were performed according to previous studies [2].

\section{Results and discussion}

The variations of gel fraction and cross-link densities calculated based on sol-gel analysis are presented in Fig. 1. It can be seen that the gel contend highly increased with the irradiation dose until $250 \mathrm{kGy}$, than still increases but slowly up to $500 \mathrm{kGy}$. The PFMs influence on gel fraction of samples cross-linked by electron beam irradiation is as follows: TMPT $>$ TAC $>$ TAIC $>$ ZDA. The results show that the higher it is the gel fraction, the more efficient the cross-linking process is. It can be observed that the most spectacular increasing of cross-link density was registered for EPDM/TMPT. Contribution of PFMs to increasing cross-link density is determined by the reactivity, the functionality and solubility of the PFMs in the EPDM rubber.

The use of these co-agents leads to an increase in crosslink density of the vulcanisate and present good compatibility with many elastomers [3, 4].

In an irradiation cured system, the gel content and crosslink density of samples increase with absorbed dose increase and this is due to the formation of a threedimensional network structure. In order to quantitatively evaluate the yields of cross-linking and chain scission of the EPDM and EPDM/PFMs rubbers irradiated with $\mathrm{EB}$, were drawn the plots of $S+S^{1 / 2}$ vs. $1 /$ absorbed dose $(D)$ from the Charlesby-Pinner equation for the different blend compositions $[1,5]$. From Fig. 2 it is observed that the sample of EPDM/TMP blends is the most effective cross-linked by electron beam irradiation. Low values of $p_{0} / q_{0}$ are suggestive for the relatively improved radicalradical interactions in polymer matrix, probably due to the decrease in free-volume $[5,6]$. 

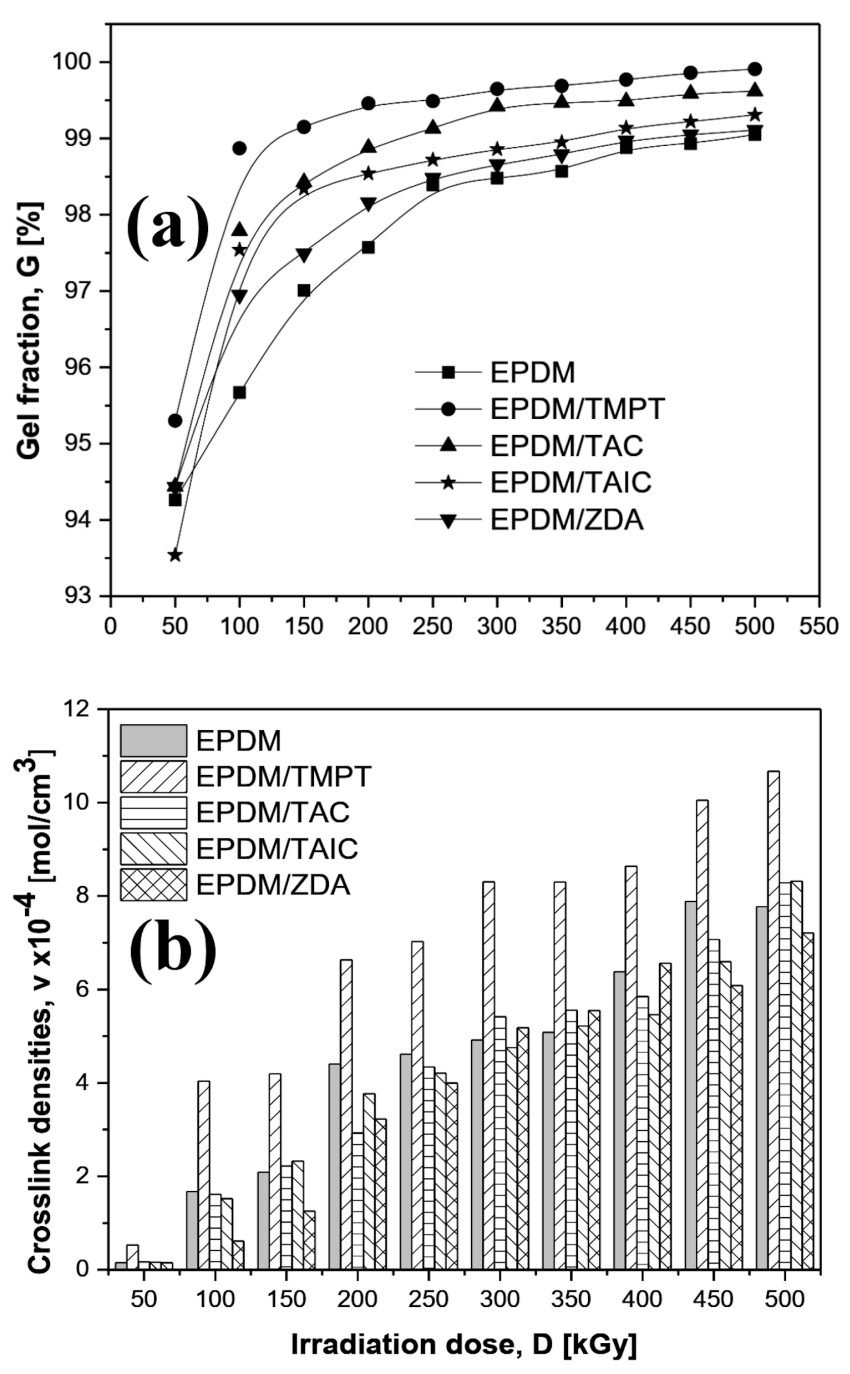

Fig. 1. The effect of irradiation dose and PFMs type on (a) gel fraction (b) and cross-link density.

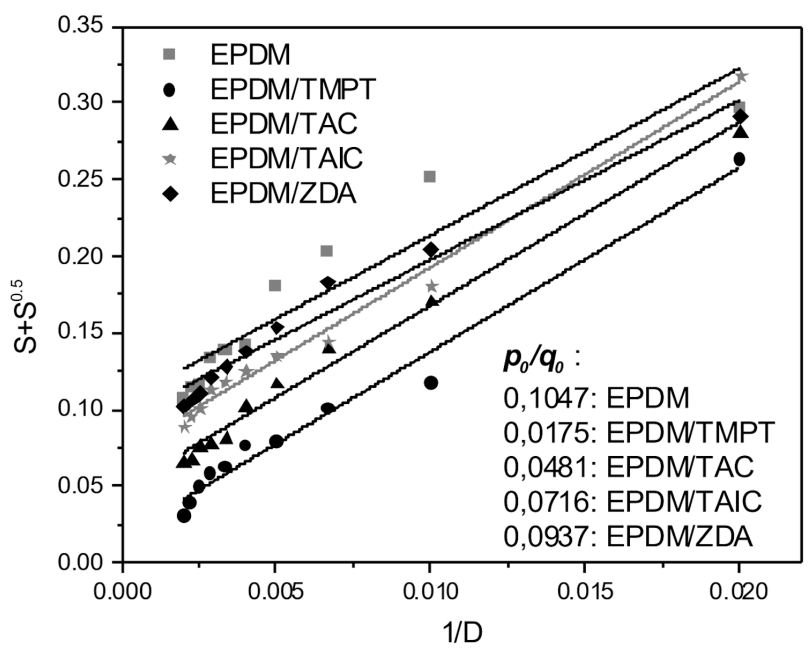

Fig. 2. The Charlesby-Pinner plot made for EPDM and EPDM/PFMs rubbers.

\section{Conclusion}

The effects of some polyfunctional monomers (TMPT, TAC, TAIC, ZDA) and irradiation dose (between 50 and $500 \mathrm{kGy})$ on the cross-linking of ethylene-propyleneterpolymer rubber (EPDM) processed by electron beam irradiation were investigated. The PFMs influence on gel fraction of cross-linked samples was as follows: TMPT $>$ TAC $>$ TAIC $>$ ZDA. The highest values for crosslink density were obtained for blend with TMPT irradiated with 500 kGy. The addition of TMPT significantly increases crosslink density when compared with the control samples, EPDM and other PFMs. By using this kind of PFMs (TMPT), not only the rate of cure is increased, but also the crosslink density or state of cure.

\section{Acknowledgments}

The researches were financed by the Romanian programs STAR ROSA - Contract No. 140/2014 and NUCLEU - Contract No. 18.13.01.02.

\section{References}

[1] D.M. Stelescu, E. Manaila, G. Craciun, J. Appl. Polym. Sci. 128, 2325 (2013).

[2] E. Manaila, G. Craciun, D.M. Stelescu, D. Ighigeanu, M. Ficai, Polym. Bull. 71, 52 (2014).

[3] R.C. Keller, Rubber Chem. Technol. 61, 238 (1988).

[4] H.G. Dikland, T. Ruardy, L. van der Does, A. Bantjes, Rubber Chem. Technol. 66, 693 (1993).

[5] K.A. Dubey, Y.K. Bhardwaj, C.V. Chaudhari, V. Kumar, N.K. Goel, S. Sabharwal, Polymer Letters 3, 492 (2009).

[6] Z.P. Zagorski, Radiat. Phys. Chem. 71, 261 (2004). 